\title{
A successful case of rescue encerclage in the mid trimester taken upto term: a case report
}

\author{
Sheelamoni A., Fathima Mithilag*, Anuradha Prasannan, Bincy A.
}

Department of Obstetrics and Gynaecology, Travancore Medical College, Kollam, Kerala, India

Received: 15 October 2020

Accepted: 02 December 2020

\section{*Correspondence:}

Dr. Fathima Mithilag,

E-mail: drfathima2691@gmail.com

Copyright: (c) the author(s), publisher and licensee Medip Academy. This is an open-access article distributed under the terms of the Creative Commons Attribution Non-Commercial License, which permits unrestricted non-commercial use, distribution, and reproduction in any medium, provided the original work is properly cited.

\begin{abstract}
Cervical encerclage has been used to treat repeated second trimester pregnancy losses. Rescue cerclage is done in cases of advanced cervical dilatation with membranes protruding into the vagina. If done correctly after proper patient selection, it can successfully prolong a nonviable pregnancy to viability. Here, we present a case report of a multiparous lady with advanced cervical dilatation at 22 weeks who had a successful rescue cerclage where the pregnancy was taken upto 38 weeks.
\end{abstract}

Keywords: Cervical incompetence, Rescue cerclage, McDonald stitch

\section{INTRODUCTION}

Cervical incompetence refers to painless cervical dilatation followed by prolapse and ballooning of membranes into the vagina and finally expulsion of an immature fetus occurring in the 2nd trimester. ${ }^{1}$ An approximate incidence of incompetence is about $0.5 \%$ in the general population and $8 \%$ in those with a previous history of 2 nd trimester pregnancy loss. It can result in recurrent pregnancy losses and preterm births. Preterm birth is one of the most important reason for perinatal morbidity and mortality. In those cases with short cervical length, performing a cervical cerclage has been found to improve the pregnancy outcome. ${ }^{2}$ The use of cervical cerclage in the prevention of preterm delivery was first described by Shirodkar in 1955 and then by McDonald two years later. ${ }^{3,4}$ It may be undertaken prophylactically in the 1 st trimester when the clinical history suggests risk of 2 nd trimester pregnancy loss. It may also be performed when there is an ultrasound diagnosis of cervical shortening $(<25$ $\mathrm{mm}) .^{5}$ More rarely, a rescue cervical stich may be performed when the patient presents with an advanced cervical dilatation with the bag of membranes bulging into the vagina. The contraindications of this procedure are fetal anomalies, signs of labor, infection, or heavy vaginal bleeding. Rescue cerclage can prolong the total duration of pregnancy, hence increasing the neonatal survival by taking these pregnancies beyond the period of viability. On evaluation of five randomized clinical trials which looked into the outcomes of elective cerclage done for clinical indications, the neonatal survival rate was about $87 \% .^{6}$ After extensive literature search, there is scarcity in data to show the efficacy of rescue cerclage. However, the risk of infection due to exposure of fetal membranes to vaginal bacteria also has to be explained to the patient and an informed written consent is to be taken. Here we present a case of successful rescue cervical encerclage in a 35-year-old multiparous woman with advanced cervical dilatation that was carried onto term.

\section{CASE REPORT}

A 35 years old lady (G3P2L1) with no known comorbidities at 22 weeks presented to our casualty with complaints of abdominal discomfort and dysuria. She had no history of abdominal pain, leaking per vaginum, fever 
or heaviness of lower abdomen. 15 years back she had a normal vaginal delivery and the baby had expired at 1 year. 2 years back she had undergone an emergency $\mathrm{C}$-section for fetal distress.

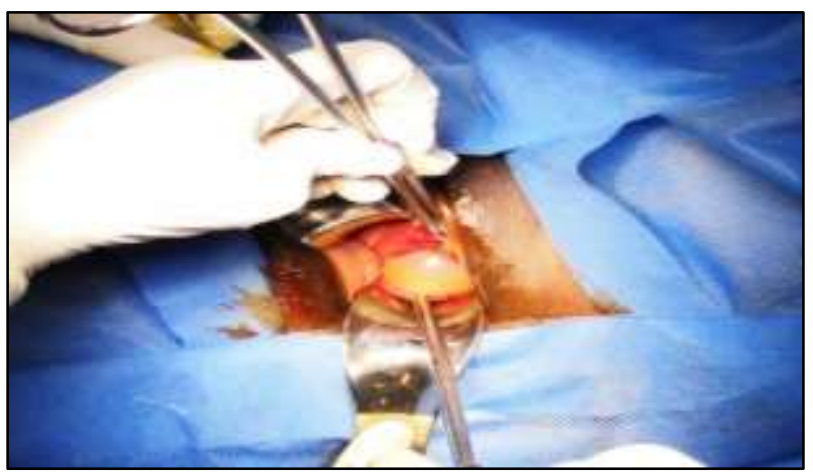

Figure 1: Bulging membranes through a well-effaced cervix.

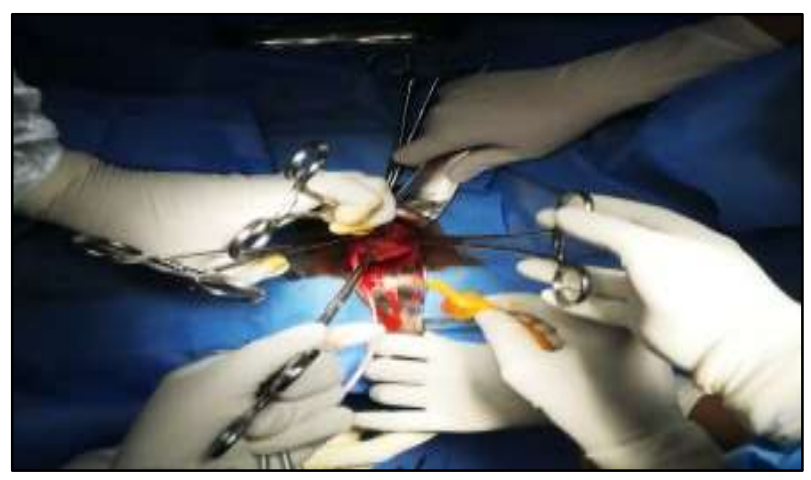

Figure 2: Foley's bulb inflated with $15 \mathrm{ml}$ saline was used to push the bag of membranes inside to procede with the cerclage.

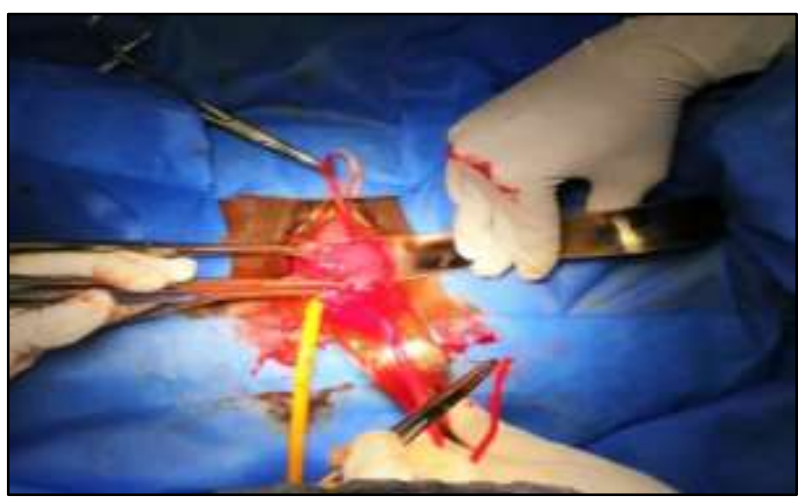

Figure 3: Merselene tape being taken all around the cervix.

She was on regular antenatal checkup at a local government hospital, was on folic acid, iron and calcium and her antenatal period was uneventful. Her NT Scan and double marker screening done at 12 weeks and anomaly scan done at 20 weeks were found to be within normal limits. At 22 weeks, an ultrasound done there revealed cervical incompetence with ballooning of membranes. She was advised termination of the pregnancy as fetal salvagability was difficult in view of advanced cervical dilatation. As she had a history of prolonged infertility following her 1st pregnancy and had only 1 live child, she was very much desirous of continuing this pregnancy and hence approached us on the same day.

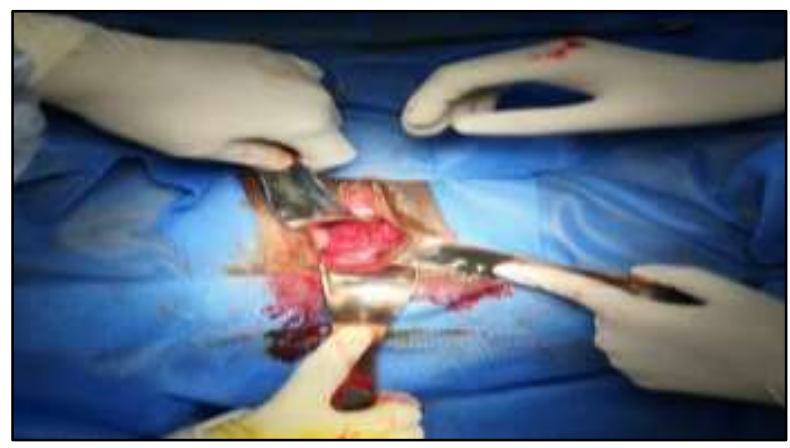

Figure 4: Cerclage insitu with the reformed cervix.

Her general condition was fair and vitals were normal. Abdominal examination revealed a gravid uterus of 22 weeks size and uterus was relaxed. On speculum examination, cervix was only $0.5 \mathrm{~cm}$ long, $3 \mathrm{~cm}$ dilated with the amniotic sac bulging into the vagina. High vaginal swab and endo cervical swab was taken. Complete blood count (CBC) and C-reactive protein (CRP) were also sent. She was planned for rescue encerclage after an emergency ultrasound sonography test (USG) without any delay. USG done showed, a single live viable intrauterine fetus corresponding to 22 weeks 3 days with no anomalies, adequate liquor volume and fundo anterior placentation. Cervix was fully taken up with membranes bulging into the vagina. Her hematological parameters including CBC and CRP were found to be normal. Urine routine and blood sugar values were also within normal limits. The patient and bystanders were explained regarding the risks and benefits of the emergency cerclage and written consent was taken for the procedure. She was taken up for emergency rescue cerclage after anesthesia clearance.

Procedure was done under spinal anaesthesia. She was placed in Trendelenberg position. On speculum examination, the cervix was fully effaced, 3 to $4 \mathrm{~cm}$ dilated with bag of membranes seen prolapsing into the vagina (Figure 1). Both lips of the cervix were very much thinned out, congested and soft. It was held with sponge holding forceps and steady gentle traction was given. A foley's bulb inflated with $15 \mathrm{ml}$ saline was used to slowly push the bulging bag of membranes (Figure 2). Mc Donald's suture with merselene tape was taken all around the cervix and knot was tied anteriorly after deflating the foley's bulb (Figure 3). Post cerclage, the reformed cervix was about $2 \frac{1}{2} \mathrm{~cm}$ long with internal os being closed (Figure 4 ). In the postoperative period, she was on complete bed rest, received intravenous antibiotics, tocolytics and progesterone supports. Ultrasound done after cerclage showed that the os was closed and the length of cervix was 
$3.2 \mathrm{~cm}$ with a distance of cerclage to external os of $1.6 \mathrm{~cm}$. After 1 week, the patient was discharged with oral antibiotics and progesterone supports. GTT was done at 24 weeks which was normal.

She was followed up with serial scans to measure the cervical length once in a fortnight. At 26 weeks, corticosteroid prophylaxis was given to accelerate fetal lung maturity. Patient had recurrent episodes of vaginitis at 28 and 30 weeks for which she was hospitalized and treated with appropriate local and systemic antibiotics after obtaining the vaginal swab culture reports and necessary blood investigations. In view of recurrent vaginal infections, blood sugar values were checked more frequently and were found to be normal. She was on close follow up. Regular scans were done to evaluate fetal growth, scar integrity, cervical length and biophysical profile. The pregnancy thrived well till 38 weeks when her elective C-section was planned. A term, live, unasphyxiated male baby of $2.848 \mathrm{~kg}$ was delivered. Cerclage suture was removed after the $\mathrm{C}$ section. After delivery, both the mother and baby had good progress in recovery and was discharged after 5 days.

\section{DISCUSSION}

For the last 60 years, cervical encerclage has been done to manage cases presenting with signs of cervical insufficiency in the second trimester. Cervical length screening is now recommended by both the American College of Obstetricians and Gynecologists and the Society for Maternal-Fetal Medicine. ${ }^{7.8}$ For women with prior preterm birth, sonographic cervical measurement is done every 2 weeks from 16 to 24 weeks. If an initial or subsequent cervical length is between 25 to $29 \mathrm{~mm}$, then a weekly interval is considered. If the cervical length measures $<25 \mathrm{~mm}$, cerclage is offered to this group of women. In women, without a history of preterm birth but with a short cervix incidentally detected sonographically, progesterone therapy is offered instead of cerclage. Contraindications to cerclage include fetal anomalies, contractions, infection, bleeding per vaginum or ruptured membranes, which significantly raises the likelihood of procedure failure.

In cases where the cervix is already found to be dilated, effaced, or both, an emergency rescue cerclage may be performed. However, there is a debate as to how late this should be performed. The challenge is that, as the gestational age at presentation increases, the greater will be the risk that surgical intervention will stimulate preterm labor or rupture of membranes. Women presenting with painless cervical dilatation in the 2 nd trimester are left with 2 options: one is expectant treatment and the other is to go ahead with rescue cerclage.

There are limited randomised controlled trials which compares the outcomes of both these methods of management. Stupin et al conducted the largest trial; this was retrospective and included 161 women with amniotic sac prolapse. The perinatal outcome was better in the cerclage group, including prolonged pregnancy, improved live birth rate and increased birth weight9. In a 10-year review of 75 women who underwent rescue cerclage procedures, Chasen and Silverman reported that only half of them delivered beyond 36 weeks. 44 percent of those with bulging membranes at the time of rescue cerclage could be taken to 28 weeks. ${ }^{10}$ In patients who were treated with emergency rescue cerclage, the factors which could lead to delivery prior to 28 weeks were reported to be, membranes bulging into the vagina, need of cerclage prior to 22 weeks gestation and nulliparity. ${ }^{11}$

A few other studies have shown significantly increased interval from encerclage to delivery, increased birth weight of the baby, better neonatal survival rate and lesser need for neonatal intensive care unit (NICU) stay in cases where rescue encerclage was done. In a study done by Debby et al patients with hourglass bulging of fetal membranes into the vagina had a shorter intervention to delivery interval than those patients without membrane protrusion. ${ }^{12}$ The intervention to delivery interval was $0-$ 14 weeks with a mean of 6 weeks. ${ }^{13}$ In our case, inspite of advanced cervical dilatation of $3-4 \mathrm{~cm}$ at 22 weeks, post cerclage the patient was successfully taken upto 38 weeks and the cerclage to delivery interval was 16 weeks which was even higher than previously mentioned cases.

Rescue cerclage definitely carries several risks. Reported adverse events are vaginal bleeding, premature preterm rupture of membranes (PPROM), chorioamnionitis, laceration of the cervix or even hysterorrhexis. In the present case, there were no complications during or after the procedure. Recurrent vaginal infections post cerclage were treated promptly and she was kept under close follow up. There was an increase in treatment to delivery interval by 16 weeks and an increase in fetal weight by $2.2 \mathrm{~kg}$.

\section{CONCLUSION}

Favourable pregnancy outcome might be evident in patients with advanced cervical dilatation in the 2 nd trimester of pregnancy following emergency cervical suturing even if performed when the membranes are bulging through the cervix into the vagina. The morbidity associated with the procedure is less and chances of fetal survival is more than $50 \%$. Hence, we recommend that this procedure may be adopted for patients with advanced cervical dilatation in the mid trimester after proper patient selection.

\section{Funding: No funding sources Conflict of interest: None declared Ethical approval: Not required}

\section{REFERENCES}

1. Cunningham FG, Leveno KJ, Bloom SL, Dashe JS, Hoffman BL, Casey BM, et al. Thyroid and other 
endocrine disorders. Williams Obstetrics. 25th edition. 2018;773.

2. Berghella V, Odibo A, To M, Rust O, Althuisius S. Cerclage for Short Cervix on Ultrasonography. MetaAnalysis of Trials Using Individual Patient-Level Data. Obstetrics and Gynecol. 2005;106(1):181-9.

3. Shirodkar VN. A new method of operative treatment for habitual abortion in the second trimester of pregnancy. Antiseptic.1955;52:299-303.

4. McDonald IA. Suture of the cervix for inevitable miscarriage. J Obstet Gynaecol Br Emp. 1957;64:34650.

5. Shirodkar VN. A new method of operative treatment for habitual abortion in the second trimester of pregnancy. Antiseptic. 1955;52:299-303.

6. J. H. Harger. Cerclage and cervical insufficiency: an evidence based analysis. The American College of Obstetricians and Gynecologists. 2020;100(6).

7. American College of Obstetricians and Gynecologists: Cerclage for management of cervical insufficiency. Practice Bulletin No. 142. 2014:2016b.

8. Society for Maternal-Fetal Medicine: Cervical cerclage for the woman with prior adverse pregnancy outcome. Reaffirmed 2015.

9. Stupin JH, David M, Siedentopf JP, Dudenhausen JW. Emergency cerclage versus bed rest for amniotic sac prolapse before 27 gestational weeks. A retrospective, comparative study of 161 women. Eur J Obstet Gynecol Reprod Biol. 2008;139:32-7.

10. Chasen ST, Silverman NS. Mid-trimester emergent cerclage: a ten year single institution review. J Perinatol. 1998;18:338.

11. Terkildsen MF, Parilla BV, Kumar P, Grobman WA. Factors associated with success of emergent secondtrimester cerclage. Obstet Gynecol. 2003;101:565-9.

12. Debby A, Sadan O, Glezerman M, Golan A. Favorable outcome following emergency second trimester cerclage. Int $\mathbf{J}$ Gynaecol Obstet. 2007;96:16-9.

13. Kumbak B, Attar R, Yildirim G, Yesildaglar N, Fiçicioglu C. Rescue cerclage in IVF pregnancies with second trimester cervical dilatation: Case report and literature review. J Turk Ger Gynecol Assoc. 2009;10:244-7.

Cite this article as: Sheelamoni A, Mithilag F, Prasannan A, Bincy A. A successful case of rescue encerclage in the mid trimester taken upto term: a case report. Int J Reprod Contracept Obstet Gynecol 2021;10:377-80. 